\title{
Editorial
}

\section{Marine Drugs Best Paper Award 2015}

\author{
Alejandro M. S. Mayer
}

Editor-in-Chief, Department of Pharmacology, CCOM, Midwestern University, 555 31st. Street, Downers Grove, IL 60515, USA; E-Mail: amayer@midwestern.edu

Received: 23 January 2015 / Accepted: 11 February 2015 / Published: 16 February 2015

Marine Drugs began a "Best Paper Award" in 2013 [1,2] to recognize outstanding papers published in our journal in the area of research, development, and production of drugs from the sea, including marine natural product chemistry. We are pleased to announce the third annual "Marine Drugs Best Paper Award" for 2015. Nominations were selected by the Editor-in-Chief and Associate Editors of Marine Drugs from all papers published in 2011; reviews and articles being evaluated separately. The following five papers have won a "Best Paper Award":

\section{Article Award:}

First Prize

Gu-Ping Hu, Jie Yuan, Li Sun, Zhi-Gang She, Jue-Heng Wu, Xiu-Jian Lan, Xun Zhu, Yong-Cheng Lin * and Sheng-Ping Chen *

Statistical Research on Marine Natural Products Based on Data Obtained between 1985 and 2008 Mar. Drugs 2011, 9(4), 514-525; doi:10.3390/md9040514

Available online: http://www.mdpi.com/1660-3397/9/4/514

Second Prize

\section{Yi Wang, Jinkai Zheng, Peipei Liu, Wei Wang and Weiming Zhu *}

Three New Compounds from Aspergillus terreus PT06-2 Grown in a High Salt Medium Mar. Drugs 2011, 9(8), 1368-1378; doi:10.3390/md9081368

Available online: http://www.mdpi.com/1660-3397/9/8/1368 


\section{Third Prize}

Maria Mansson *, Anita Nielsen, Louise Kjærulff, Charlotte H. Gotfredsen, Matthias Wietz, Hanne Ingmer, Lone Gram and Thomas O. Larsen

Inhibition of Virulence Gene Expression in Staphylococcus aureus by Novel Depsipeptides from a Marine Photobacterium

Mar. Drugs 2011, 9(12), 2537-2552; doi:10.3390/md9122537

Available online: http://www.mdpi.com/1660-3397/9/12/2537

\section{Review Award:}

\section{First Prize}

\section{Guangling Jiao, Guangli Yu *, Junzeng Zhang and H. Stephen Ewart *}

Chemical Structures and Bioactivities of Sulfated Polysaccharides from Marine Algae Mar. Drugs 2011, 9(2), 196-223; doi:10.3390/md9020196

Available online: http:/www.mdpi.com/1660-3397/9/2/196

\section{Second Prize}

\section{Sinéad Lordan, R. Paul Ross and Catherine Stanton *}

Marine Bioactives as Functional Food Ingredients: Potential to Reduce the Incidence of Chronic Diseases

Mar. Drugs 2011, 9(6), 1056-1100; doi:10.3390/md9061056

Available online: http://www.mdpi.com/1660-3397/9/6/1056

The Prize Awarding Committee has concluded that the five papers selected have become valuable contributions to Marine Drugs, as well as global marine drug discovery research, and, thus, together with the Editorial Board of Marine Drugs, we would like to congratulate the authors of these five articles for the significance of their scientific contributions. In recognition of their accomplishments, Dr. Sheng-Ping Chen, Dr. Weiming Zhu, and Dr. Maria Mansson will receive a prize of $600 \mathrm{CHF}$, $400 \mathrm{CHF}$, and $200 \mathrm{CHF}$, respectively, as well as the privilege to publish an additional paper free of charge in open access format in Marine Drugs, after the standard peer-review procedure. Dr. H. Stephen Ewart and Dr. Catherine Stanton will also be awarded the privilege of publishing an additional research paper, free of charge, in open access format in Marine Drugs, after the standard peer-review procedure has been completed.

\section{Prize Awarding Committee}

\section{Editor-in-Chief}

\section{Prof. Dr. Alejandro M. S. Mayer}

Department of Pharmacology, CCOM, Midwestern University, 555 31st. Street, Downers Grove, IL 60515, USA

E-Mail: amayer@midwestern.edu 
Associate Editor

\section{Prof. Dr. Jordan K. Zjawiony}

Department of BioMolecular Sciences, School of Pharmacy, University of Mississippi, MS 38677, USA

E-Mail: jordan@olemiss.edu

\section{Associate Editor}

\section{Prof. Dr. Orazio Taglialatela-Scafati}

Dipartimento di Farmacia, Universita' di Napoli Federico II, Via Montesano 49, I-80131 Napoli, Italy E-Mail: orazio.taglialatelascafati@unina.it

\section{Associate Editor}

\section{Dr. Keith B. Glaser}

AbbVie, 1 North Waukegan Road, North Chicago, IL 60064, USA

E-Mail: keith.glaser@abbvie.com

\section{Associate Editor}

\section{Dr. Peer B. Jacobson}

AbbVie, 1 North Waukegan Road, North Chicago, IL 6004-6099, USA

E-Mail: peer.b.jacobson@abbvie.com

\section{References}

1. Han, O. Marine Drugs Best Paper Award 2013. Mar. Drugs 2013, 11, 581-583.

2. Mayer, A.M.S. Marine Drugs Best Paper Award 2014. Mar. Drugs 2014, 12, 1157-1159.

(C) 2015 by the authors; licensee MDPI, Basel, Switzerland. This article is an open access article distributed under the terms and conditions of the Creative Commons Attribution license (http://creativecommons.org/licenses/by/4.0/). 